Int. J. Electrochem. Sci., 11 (2016) 8016 - 8026

\title{
Thulium (III) Hexacyanoferrate Star Fruit-Like Structure Modified Electrode for L-Cysteine Electrochemical Sensor
}

\author{
Mani Sakthivel, Mani Sivakumar, Shen-Ming Chen*, Wei Lun-Cheng \\ Electroanalysis and Bioelectrochemistry Lab, Department of Chemical Engineering and \\ Biotechnology, National Taipei University of Technology, Taipei 10608, Taiwan. \\ *E-mail: smchen78@ms15.hinet.net
}

doi: $10.20964 / 2016.09 .09$

Received: 26 May 2016 / Accepted: 5 July 2016 / Published: 7 August 2016

\begin{abstract}
We report the preparation of star fruit-like thulium hexacyanoferrate (TmHCF) by using one-step electrochemical deposition in cyclic voltammetry technique. The electrochemically deposited star fruit-like TmHCF is exhibit unique electrocatalytic activity towards the detection of L-cysteine (LCys). The as-prepared TmHCF was characterized using different techniques such as scanning electron microscopy (SEM), X-ray diffraction (XRD), electrochemical impedance spectroscopy (EIS). The electrochemical activity of star fruit-like TmHCF was studied using cyclic voltammetry (CV), and differential pulse voltammetry (DPV). The modified electrode shows a considerable linear range, sensitivity and detection limit of about 0.5 to $8.92 \mu \mathrm{M}, 48.479 \mu \mathrm{A}_{\mu} \mathrm{M}^{-1} \mathrm{~cm}^{-2}$ and $16 \mathrm{nM}$ respectively. Furthermore, the modified electrode was tested in the real samples analysis in urine and river water samples.
\end{abstract}

Keywords: Thulium hexacyanoferrate (TmHCF), electrochemical sensor, L-cysteine.

\section{$\underline{\text { FULL TEXT }}$}

(C) 2016 The Authors. Published by ESG (www.electrochemsci.org). This article is an open access article distributed under the terms and conditions of the Creative Commons Attribution license (http://creativecommons.org/licenses/by/4.0/). 